\title{
11 \\ A CONCEPÇÃO MULTIFACETADA DE NATUREZA EM KANT
}

Rosalvo Schütz

\begin{abstract}
RESUMO - Kant desenvolveu três grandes concepções de natureza. Cada uma corresponde e é viabilizada em uma de suas Críticas. Na primeira Crítica, a natureza é o conjunto do conhecimento que nos é possibilitado através do entendimento e representa a natureza mecânico-causal. É a natureza da qual trata a ciência. Na segunda Crítica nos é evidenciada uma natureza que transcende nossa sensibilidade e é fruto da razão que cria suas próprias leis. É a natureza suprassensível, que fundamenta a liberdade e o agir prático-ético. Na terceira Crítica é tratada a natureza orgânica que é, ao mesmo tempo, causa e efeito de si mesma e é viabilizada pelo entendimento intuitivo. As diferentes concepções de natureza são formas diferenciadas de conhecimento, elaboradas a partir de princípios diversos. Todas, no entanto, são legítimas e não se excluem.
\end{abstract}

PALAVRAS-CHAVE - Natureza. Mecanismo. Liberdade. Organismo.

\begin{abstract}
Kant developed three major conceptions of nature. Each one is made possible by and corresponds to one of his Critiques. In the First Critique, nature is the ensemble of knowledge that is made possible through the understanding and represents the mechanical-causal nature. This is nature as it is dealt with by science. In the Second Critique we are presented a conception of nature that transcends our sensibility and results from reason as it creates its own laws. This is supersensible nature, as it grounds freedom and the practical-ethical actions. In the Third Critique we have organic nature, which is, at once, cause and effect of itself and is made possible by intuitive understanding. The different conceptions of nature are differentiated forms of knowledge, elaborated from diverse principles. And yet the three forms of nature are legitimate and do not exclude the other two.
\end{abstract}

KEY WORDS - Freedom. Mechanism. Nature. Organism.

\section{Introdução}

As ciências naturais reivindicam, com sucesso progressivo, serem as únicas portadoras de conhecimentos efetivamente válidos sobre a natureza. Para tanto, elas pressupõem uma concepção de natureza muito peculiar. Kant desenvolveu pelo menos três concepções de natureza e apenas uma destas corresponde àquela concepção pressuposta pelas ciências naturais. Segundo ele nenhuma delas significa o que é a natureza mesma, pois são antes possibilidades diferenciadas de conhecimento que possuímos. Esta possibilidade de compreensão multifacetada da natureza, demonstrada por Kant, nos torna mais precavidos contra uma visão unilateral e amplia nossos horizontes de

Professor Adjunto do curso de Filosofia e do PPG em Filosofia da UNIOESTE.

\begin{tabular}{|l|l|l|l|l|l|}
\hline VERITAS & Porto Alegre & v. 54 & n. 1 & jan./mar. 2009 & p. 238-256 \\
\hline
\end{tabular}


interação com ela. Esta postura é algo que, diante do progressivo processo de destruição ambiental, é carregada de grande importância.

Um primeiro significado de natureza, explicitado por Kant na Crítica da Razão Pura (CRP) e nos Prolegômenos (Prol.), é limitado por regras causais e objetivas. Nas regras objetivas, aí pressupostas, não pode mais surgir um sujeito. Nesta natureza, nós, como sujeitos livres e orgânicos, não podemos ser tematizados. Para poder conceber o sujeito livre, Kant precisou desenvolver uma outra concepção de natureza, que não se restringe a esta, pois que, a partir das ciências da natureza (que se edificam em cima do pressuposto da causalidade) é impossível fazer qualquer referência à liberdade. Com a ideia de uma natureza suprassensível, desenvolvida especialmente na Crítica da Razão Prática (CRPr), Kant concebe uma outra concepção de natureza por meio da qual se torna possível tematizar a liberdade humana. O problema com o qual Kant se defronta é, então, o de que não existe nenhum elo de ligação entre esses dois sistemas, ou seja, entre o que se refere às regras objetivas e o que se refere ao sujeito livre. Além disto, também estava claro para Kant que, ao priorizarmos a concepção de natureza derivada das regras objetivas, não podemos mais conhecer e compreender a natureza em sua totalidade, pois, naquelas, somente a representação interna e isolada (Inbegriff) de unidades pode ser conhecida, e a natureza não pode mais ser tematizada como totalidade orgânica.

Segundo Kant, a natureza não se reduz, no entanto, a regras objetivas, causais e isoladas e nem mesmo a natureza suprassensível, revelada por nossa natureza prático-ética. Por isto buscou fundamentar mais uma possibilidade de compreensão de natureza em sua Crítica da Faculdade do Juízo. Nela parte do pressuposto de que todos nós nos confrontamos constantemente com diversas formas de organismos (animais e vetais). Segundo nosso autor, é evidente que, nesses casos, nos defrontamos com algo que já existe antes mesmo de que façamos qualquer esforço de apreensão ou mesmo de objetificação. Seríamos, portanto, a partir deste ponto de vista, obrigados a desenvolver uma ideia de natureza na qual os organismos, inclusive nós mesmos, enquanto seres vivos que somos, sejam possíveis. Caso contrário, nosso conhecimento da natureza seria necessariamente unilateral e limitado.

Ao explicitar e confrontar as concepções de natureza em Kant, pretendemos contribuir com a legitimação de diferentes formas de conhecimento e compreensão da natureza, assim como, pelo confronto mútuo, explicitar a concepção de natureza específica pressuposta pelas ciências naturais.

\section{A natureza da qual trata a ciência}

Na Crítica da Razão Pura e nos Prolegômenos, Kant explicitou a concepção de natureza possível na medida em que nós a concebemos e conhecemos enquanto regrada por objetividade causal. Seu objetivo principal, com isto, era traçar os limites do conhecimento científico, ou seja, os limites do conheci- 
mento objetivo-causal, para depois poder afirmar o que se pode esperar da filosofia, o seja, daquilo que ultrapassa esse tipo de conhecimento.

A concepção aí desenvolvida pode ser vista, por um lado, como o resultado de uma tradição que fez da matematização do conhecimento (racionalismo) a novidade da ciência moderna. Com a matematização da ciência se objetivava poder prever fenômenos com certeza matemática. Poder prever foi e é condição da tecnologia. Só conhecendo leis objetivas e matematizáveis é que se torna possível vencer o acaso na projeção e na construção de instrumentos inéditos. Quanto mais previsíveis e matematizáveis forem as regras da natureza, mais elas podem se tornar aproveitáveis, instrumentalizáveis, ou seja, mais facilmente elas podem se transformar em tecnologia. Descartes, por exemplo, que é caracterizado como um dos grandes propulsores dessa tradição, perguntava-se sobre o que nos é o mais evidente e do qual não podemos duvidar de forma alguma? Eu penso, foi sua resposta. A partir deste pressuposto indubitável, Descartes desdobrou diversas consequências racionais que se apresentavam como necessárias. O pensamento, portanto, logicamente necessário e universalmente válido, tornou-se fonte de conhecimento. A pergunta em torno do que esses conhecimentos evidentes e racionais tinham a ver com a natureza, Descartes não conseguiu resolver sem apelar para Deus. Só em Deus estaria essa unidade. Por outro lado, o empirismo, que se contrapunha à tradição racionalista, afirmando que a experiência é a única fonte de conhecimento, também é constituidora dessa tradição. O pensamento, assim afirmava, por exemplo, John Locke, no máximo une os diversos dados da experiência. David Hume radicalizou a concepção empirista ao afirmar que até mesmo noções como a de causalidade são um constructo que nós mesmos fizemos a partir dos costumes e dos hábitos, e que esse tipo de noções de forma alguma pode ser racionalmente dedutível. Assim, por exemplo, vemos o sol nascer todo dia e, por isto, dissemos que ele irá nascer amanhã, embora não exista nenhuma certeza racional necessária para tal. Apenas não vivemos uma outra situação. A teoria de Leibniz, no entanto, cunhada pela tendência racionalista, se contrapunha a Hume ao dizer que jamais poderíamos afirmar a causalidade apenas a partir da experiência. Que a afirmação empirista de que no entendimento não existe nada que não provenha dos sentidos deveria ser complementada com a seguinte afirmação: "com acessão do entendimento mesmo". Nesse ambiente filosófico, aqui brevemente apontado, Kant desenvolveu sua teoria, que busca, ao mesmo tempo, superar ambos os partidos sem, no entanto, negar nenhum por completo.

Na continuidade dessa tradição, Kant se pergunta como que é possível chegar a um novo conhecimento e afirmá-lo como verdadeiro. Ou seja, como é possível, a partir das sensações que nos chegam pelos sentidos, poder afirmar algo novo com pretensão de validade universal. Num juízo analítico, onde o predicado já está contido no sujeito, torna-se pouco problemático afirmar algo verdadeiro, bastando, para tanto, lançar mão de leis lógicas elementares, no entanto, ele, a rigor, não contém nada de novo. Já nos juízos sintéticos, o 
predicado afirma algo novo em relação ao sujeito, possibilitando, por isto, o avanço das ciências. Como, porém, afirmar a universalidade de sua validade? A questão é saber como chegar a juízos que, ao mesmo tempo, apresentem algo de novo, mas que também possam ser considerados como verdadeiros e até mesmo necessários, pois, sem a possibilidade de poder prever com certeza calculável algo novo, a ciência não é possível. Para tanto, além da diferenciação entre juízos analíticos e sintéticos, Kant introduziu uma outra distinção • trata-se dos juízos a priori e dos a posteriori. Segundo ele, existem juízos que nós só podemos fazer a partir de experiências empíricas (a posteriori), mas existem outros que podem ser feitos independentemente de qualquer experiência (a priori). Os juízos a priori podem ser feitos com uma certeza que se fundamenta exclusivamente em regras contidas em nossa razão (racionalismo). Dentro do quadro de possibilidades, possível diante desta dupla distinção, Kant interessou-se pelos juízos sintéticos a priori por serem a única ${ }^{1}$ hipótese na qual seria possível equacionar empirismo e racionalismo, novidade com verdade. O grande desafio que Kant se coloca, portanto, é como seria possível fazer afirmações que apresentem algo novo, ou seja, sintéticas, mas que, ao mesmo tempo, pudessem ser feitas de forma a priori, ou seja, validadas por regras universais. É dessa situação que surgiu a famosa pergunta: "Como são possíveis juízos sintéticos a priori?"

Kant toma a argumentação de Hume, de que a causalidade não existe na realidade, que ela é algo decorrente de nossos costumes e hábitos e a refina. Segundo Kant, ela realmente não existe em uma realidade fora de nós, mas também não é apenas decorrência do hábito. Segundo nosso autor, ela corresponde a leis que estão em nós mesmos. Não as determinações específicas das leis, mas as leis mesmas, provêm dos sujeitos. Em base a isto, podemos, dentro de circunstâncias determinadas, prever fenômenos com certeza matemática, mesmo que antes nunca os tenhamos presenciado.

Segundo nosso autor, as formas de percepção - espaço e tempo - e as categorias do entendimento - qualidade, quantidade, relação e modalidade - são as condições a priori de qualquer possibilidade de conhecimento científico. Com referência a elas, e não a uma realidade fora de nós, é que é possível a universalidade científica. Tudo que vem a nós pelas experiências sensíveis só pode vir a nós através destas categorias e dentro das formas de percepção disponíveis. Ao mesmo tempo, porém, diferentemente dos racionalistas, sem a experiência sensível o conhecimento também não seria possível. Aquilo, portanto, que chamamos de natureza no conhecimento científico é, sempre e apenas, aquilo que nós mesmos, dentro dos limites e através dessas condições previamente dadas, podemos afirmar da natureza. Não podemos, de forma alguma, afirmar que isto é a natureza em si (numenum). É apenas a forma como ela nos aparece (fenomenum) dentro desses limites. De acordo com

Uma vez que juízos analíticos são sempre a priori; juízos analíticos a posteriori não podem existir e juízos a posteriori são sempre sintéticos (cf. Höffe, 2005, 49). 
estas categorias e formas de percepção, ou seja, das regras inerentes a elas mesmas, podemos estabelecer as mais diversas conexões. Viabiliza-se, assim, o juízo sintético a priori. São juízos que, ao mesmo tempo, apresentam algo novo, mas são constituídos conforme as regras necessárias do entendimento. Ou seja, podemos afirmar, com certeza, como seria algo futuramente, se acontecer segundo estas regras. Viabiliza-se, assim, a previsibilidade, a possibilidade de efetivação tecnológica. Neste sentido, a "natureza é a existência de coisas enquanto determinadas por leis universais" (Prol. § 14), e apenas isto. Não podemos, porém, ter acesso ao que seria a natureza em si mesma (ao numenum), nem de forma a priori, nem a posteriori. A natureza é, tãosomente, um constructo nosso, aquilo que nós, munidos de nossas categorias do entendimento e de nossas formas de percepção, podemos afirmar da mesma. "A natureza considerada, portanto, materialiter é o conjunto de todos os objetos da experiência" (Prol. § 16) ${ }^{2}$. Se os conceitos com os quais definimos a natureza nas ciências se referem realmente a objetos, ou se são apenas "coisas da mente" (Gedankendingen), isto não tem como ser decidido, e também não tem importância para a ciência. Esta "regularidade de todos os objetos da natureza" (notwendige Gesetzmäßigkeit der Erfahrung), à qual toda experiência já está sempre e necessariamente submetida, pode ser conhecida a priori. Conhecer estas condições a priori é a possibilidade de uma ciência natural pura. Não se trata, no entanto, de extrair regras da natureza através da observação:

[...] não nos ocupamos aqui com coisas em si mesmas (estas suas propriedades não nos interessam), mas apenas com coisas enquanto objetos de uma possível experiência, e o conjunto das mesmas é que denominamos aqui natureza. [...] Penso que compreenderão: não me refiro aqui às regras de observação da uma natureza já dada, pois elas já pressupõe experiência; nem, por conseguinte, à maneira como podemos aprender da natureza (pela experiência) as leis, pois estas não seriam leis a priori e não dariam nenhuma ciência pura da natureza; mas pretendo mostrar como as condições a priori são, ao mesmo tempo, as fontes da possibilidade da experiência, das quais devem ser derivadas as leis universais da natureza (Prol. § 17).

Para além do que nos é apresentado pelas experiências sensíveis, portanto, existem conceitos que têm sua origem a priori, fora da experiência e em nós mesmos. Aquilo que parece ser uma propriedade dos objetos, pelos quais nós chegamos ao que chamamos uma validade objetiva, não é nada mais do que a "validade universal necessária" (Allgemeingültigkeit) que repousa na recorrência a puros conceitos do entendimento. É isto que possibilita um juízo objetivo. Ou seja, "os juízos da experiência tiram sua validade objetiva não do conhecimento imediato do objeto (pois isto é impossível), mas apenas das condições de validade universal dos juízos empíricos, a qual repousa "[...]

\footnotetext{
"Natur also materialiter betrachtet ist der Inbegriff aller Gegenstände der Erfahrung."
} 
nunca sobre condições empíricas, nem em geral sobre condições sensíveis, mas sobre um conceito do entendimento puro" (Prol. § 19). Antes que a observação, a percepção sensível, possa ser considerada experiência e expressar conhecimento, existem conceitos do entendimento, que lhes dão validade objetiva. Estes são conceitos existentes de forma puramente a priori no entendimento. Assim, por exemplo, o conceito de causalidade: "O conceito de causa é, portanto, um conceito de entendimento puro, inteiramente distinto de toda possível percepção, servindo apenas para determinar a percepção que lhe é subordinada, relativamente ao juízo em geral, e, por conseguinte, para tornar possível um juízo universalmente válido" (Prol. § 20).

Para que algo possa ser considerado experiência (Erfahrung) - o que, ademais, para Kant equivale a conhecimento (Erkenntnis) - foram percorridos diversos níveis. O caminho foi iniciado pela percepção (Wahmehmung) sensível passando pelas categorias do entendimento (Verstandesbegriffe), que então as pensa e as concilia enquanto representação (Vorstellung). Como resultado temos os juízos. Esses juízos podem ser subjetivos e, portanto, sem validade universal, na medida em que se reduzem a um único sujeito, ou objetivos, na medida em que sua representação se dá na consciência de forma necessária e com validade universal. Ocorre que, mesmo no segundo caso, eles não se referem a uma realidade ontológica, mas à evidência intersubjetiva garantida pelas associações regradas pelas categorias do entendimento, que nos são dadas de forma a priori. As regras que possibilitam esta pretensão de validade universal são, por isto, princípios (Grundsätze) a priori de qualquer possibilidade de experiência, ou seja, de conhecimento. "Os juízos, enquanto considerados mera condição da união de representações dadas numa consciência, são regras. Essas regras, na medida em que representam a união como necessária, são regras a priori, e, enquanto não houver nenhuma outra acima delas, da qual possam ser derivadas, são princípios" (Prol. § 23).

Assim, a questão de como é possível uma ciência pura da natureza (reine Naturwissenschaft) está solucionada. Toda a natureza, no entanto, está reduzida ao que nos pode ser apresentado pela experiência, que, no entanto, está submetida a condições necessárias e a priori, ditadas por nosso entendimento. Não se trata, para a ciência, da natureza em si, mas da natureza como ela se apresenta enquanto fenômeno para nós. Assim, a multiplicidade de diferentes fenômenos pode ser submetida a denominadores comuns, estes contidos em nosso entendimento. Esses fenômenos, por sua vez, se tornaram comparáveis, previsíveis, calculáveis, tornando possível, assim, aplicar a matemática sobre a natureza. Como afirma Kant, no § 26 dos Prolegômenos: "é justamente isto que possibilita a aplicação da matemática à natureza, no que diz respeito à intuição sensível, pela qual nos é dada e determinada". Os juízos sintéticos a priori, portanto, não se referem às conexões existentes nas coisas em si mesmas (in der Verknüpfungen der Dinge an sich selbst), mas são simplesmente juízos conforme leis universais do entendimento. Essas leis, no entanto, só são possíveis, são uma realidade, à medida que se explicitam na experiência. Não 
que a experiência as produza pelo hábito, como pensava Hume, mas pelo contrário, é só através delas que a própria experiência é possível. O que existe de forma a priori, no entanto, é algo de caráter apenas formal e não pode afirmar nada a priori (sem experiência) em relação ao conteúdo, como acreditavam os racionalistas. É daí que Kant extrai a afirmação de que "o entendimento não cria suas leis (a priori) a partir da natureza, mas as prescreve à mesma" (Prol. § 36).

Para a ciência, portanto, a natureza é reduzida ao fenômeno como ele nos aparece, e como nós a conhecemos dentro dos limites de nosso entendimento - o ser das coisas à medida que estas são determinadas por leis universais contidas em nós mesmos. Isto, no entanto, não exclui a possibilidade de existirem coisas em si, ou seja, coisas que, dentro dos limites descritos, não sejam perceptíveis. A natureza, portanto, pode ser muito mais do que aquilo que nos é perceptível dentro destas fronteiras. Nem mesmo é possível afirmar que na natureza tudo é causalmente determinado e esta é a dedução crítica que Kant faz no § 32 dos Prolegômenos: "Nossa dedução crítica não exclui de maneira alguma tais coisas (numena), mas só limita os princípios da estética, de modo a não se estenderem a todas as coisas, o que transformaria tudo em meros fenômenos, mas a serem válidos somente como objetos de uma experiência possível". Tudo, pois, que não se deixa reduzir às categorias do entendimento (qualidade, quantidade, relação e modalidade) e às formas de percepção (espaço e tempo) não pode ser tematizado pela ciência moderna. Kant indica, assim, com exatidão, as condições de utilização das ciências.

Kant estava convencido de que a natureza, humana e não humana, eram muito mais do que isto. Ao definir as condições de possibilidade da ciência moderna, na verdade, Kant evidenciou seus limites. Para ela é impossível tematizar questões como a responsabilidade ética, a liberdade ou mesmo a unidade orgânica e autocriadora da natureza, uma vez que estas questões ultrapassam seus limites. Sempre que a ciência ultrapassa estes limites, segundo Kant, ela não percebe que "com seus conceitos aliás legítimos, foi além dos limites de seu uso" (Prol. § 33).

A concepção de natureza aqui explicitada por Kant é a expressão do significado que, de modo geral, a natureza assume para as ciências modernas. Respaldado pelo argumento da utilidade tecnológica, este significado muitas vezes é apresentado como a única compreensão verdadeira da mesma. Consequentemente, a natureza não pode ser compreendida e concebida como tendo uma realidade em si, como sendo uma realidade autônoma, pois é apenas o sujeito conhecedor que se impõe sobre uma natureza que só pode mais ser concebida como objeto morto ${ }^{3}$. Com a separação entre o mundo fenomêni-

\footnotetext{
Segundo Schelling, em seu escrito sobre a Essência da Liberdade Humana, este é um problema da qual sofre toda a filosofia europeia moderna: "Toda a filosofia europeia moderna, desde o seu início (com Descartes), tem esta falta generalizada que consiste no fato de que, para ela, a natureza não está presente e escapa-lhe um fundamento vivo" (Schelling, 1993, p. 60).
} 
co e o mundo das coisas em si, Kant deixou claro que a ciência empíricomatemática só pode reunir as impressões de nossos sentidos conforme categorias de nosso entendimento, nunca, no entanto, compreender a natureza como sua própria relação de efeitos (Wirkungszusammenhang).

\section{A natureza suprassensível da autonomia prático-ética}

Esta rigorosa delimitação do que pode significar natureza para as ciências empírico-matemáticas modernas não se deixa reduzir simplesmente a um sentido negativo e restringidor. Pelo contrário, se todo o nosso conhecimento formatado pelas formas de percepção e entendimento é sempre e apenas uma expressão do mundo fenomênico, libera-se de sua determinação tudo aquilo que não pode ser enquadrado nas mesmas formas. Quando essas ciências buscam interferir na realidade em si estão ultrapassando seus limites e indo para uma esfera para a qual não possuem instrumentos adequados. Nessa esfera da realidade em si, por exemplo, estamos também nós enquanto sujeitos livres. No mundo fenomênico, tal como ele se apresenta através das categorias de entendimento, a liberdade simplesmente não pode ser pensada. Assim, para nos podermos pensar enquanto sujeitos livres, a concepção de natureza que é pressuposta pelas ciências empírico-matemáticas não é suficiente, pois nela tudo é causalmente necessário e calculável. Como, no entanto, a realidade é muito mais do que aquilo de que tratam as ciências/fenômenos, a liberdade continua podendo ser pensada. Liberdade enquanto causalidade independente de causas estranhas, ou seja, que tenha sua origem apenas na autonomia da razão.

O fato, portanto, de podermos, enquanto seres racionais, agir independentemente de causas estranhas e ultrapassar, assim, o âmbito dos sentidos, nos torna livres. Na Crítica da Razão Pura, Kant recoloca a questão na medida em que constata a existência de uma antinomia fundamental na razão pura, qual seja: no mundo fenomênico, onde tudo acontece conforme nossas categorias de entendimento, a liberdade não pode ser pensada, mas reconhece também que existe uma causalidade que não se deixa reduzir a uma causalidade calculável: aquela dos sujeitos em ação (handelde Subjekt). "Numa palavra, a sua causalidade, na medida em que é intelectual, não se incluiria na série das condições empíricas que tornam necessário o acontecimento no mundo sensível" (CRP, 467). Se os fenômenos como eles nos aparecem fossem as coisas em si, a liberdade simplesmente não seria possível. Por isso, quando a realidade fenomênica é apresentada com sendo realidade absoluta, ela tem influência negativa sobre a razão, pois não permite mais a tematização de qualquer coisa que ultrapasse esses limites restritos. Kant nos adverte contra a tentação de buscarmos entender a liberdade a partir do mundo fenomênico: "E aqui a hipótese comum, mas enganosa, da realidade absoluta dos fenômenos, mostra bem quanto é prejudicial o seu efeito de confundir a razão. Pois que, se os fenômenos são coisas em si, não é possível salvar a liberdade" (CRP, 465). Na 
Fundamentação da Metafísica dos Costumes (FMC) esta constatação é claramente expressa enquanto contraposição entre liberdade e necessidade natural:

A vontade é uma espécie de causalidade dos seres vivos, enquanto racionais, e liberdade seria a propriedade desta causalidade, pela qual ela pode ser eficiente, independentemente de causas estranhas que a determinem; assim como necessidade natural é a propriedade da causalidade de todos os seres irracionais de serem determinados à atividade pela influência de causas estranhas (FMC, 148).

O objetivo da Fundamentação da Metafísica dos Costumes e da Crítica da Razão Prática (CRPr) é justamente tratar essa dimensão que dá aos humanos, enquanto seres racionais, a possibilidade da ação ética, ou seja, "a propriedade da vontade de ser lei para si mesma" (FMC, 149), a possibilidade de decidir sobre sua ação de forma não pré-calculável por ciência empírico-matemático alguma. Segundo o autor, mesmo que nós nunca possamos ter uma certeza científico-teorética deste fato, nós somos conscientes do mesmo de forma direta na medida em que agimos conforme regras e princípios fundados exclusivamente na razão. Se, por um lado, de forma alguma são possíveis conhecimentos científico-teoréticos sobre nós enquanto participantes de um mundo inteligível, por outro lado, temos certeza da existência do mesmo na medida em que são para nós conceitos práticos dos quais constantemente fizemos uso, por isto esta seria a esfera da razão prática.

Para afirmar a existência da liberdade, Kant não toma nem uma aceitação da liberdade com algo que nos é diretamente consciente, mas também não como resultado das experiências que fizemos no mundo fenomênico. A referência factual que nos leva à ideia de liberdade seria a lei moral, que seria o único fato da razão pura (das einzige Faktum der reinen Vernunft). Nas palavras de Kant: "[...] a lei moral, da qual nos tornamos imediatamente conscientes (tão logo projetamos para nós máximas da vontade), que se oferece primeiramente a nós e que, na medida em que a razão a apresenta como um fundamento determinante sem nenhuma condição sensível preponderante, antes, totalmente independente delas, conduz diretamente ao conceito de liberdade (CRP, 103). A lei moral, portanto, enquanto não causada por vontade heterônoma alguma, seria o faktum da razão que nos torna diretamente conscientes de nossa liberdade. Lei moral, liberdade e razão, de certa forma, podem aqui ser tomados como sendo sinônimas. Surge, assim, a necessidade de se conceber uma outra natureza, que permita a tematização do ser humano como ser livre, ético, e que tem capacidade de - embora isto pareça impossível do ponto de vista empírico-causal e nós não sabermos como isto acontece - interferir no mundo fenomênico, de forma a causar aí efeitos que não são compreensíveis pelo entendimento com suas categorias a priori ${ }^{4}$. No agir moral, ou seja,

Isto se torna possível na medida em que Kant concebe a razão como algo mais amplo do que o entendimento: "Ora, o homem encontra em si mesmo uma faculdade pela qual se distingue de to- 
no agir conforme leis fundadas exclusivamente na razão e, portanto, num agir livre de causas estranhas à razão, passamos a agir e nos situar num mundo suprassensível. Damo-nos conta, assim, de uma natureza suprassensível, para além das determinações empírico-causais do mundo fenomênico, que repousa na autonomia da razão. Essa natureza suprassensível se caracterizaria, fundamentalmente, por sua independências em relação às condições empíricas, diferenciando-se, assim, das leis da natureza sensível:

A natureza sensível de entes racionais em geral é a existência dos mesmos sob leis empiricamente condicionadas, por conseguinte é heteronomia para a razão. A natureza supra-sensível dos mesmos entes é, ao contrário, a sua existência segundo leis que são independentes de toda a condição empírica, que, por conseguinte, pertencem à autonomia da razão pura (CRPr, 143).

A autonomia dos sujeitos humanos frente às determinações fenomênicas leva, pois, a pressupor uma outra natureza da qual estes comungam enquanto seres racionais. E "a natureza supra-sensível, na medida em que podemos formar um conceito dela, não é senão uma natureza sob a autonomia da razão prática pura" (CRPr, 143). Natureza suprassensível (übersinnliche Natur) que, mesmo não podendo ser afirmada como sendo a coisa em $\mathrm{Si}^{5}$, aponta para uma realidade na qual nós somos possíveis como seres incondicionados e autônomos. Segundo Kant, é a própria razão que o reconhece: "Pois é a nossa própria razão que reconhece a si mediante a lei prática suprema e incondicionada e ao ente, que é autoconsciente dessa lei (nossa própria pessoa), como pertencente ao mundo puro do entendimento e, em verdade, como a determinação até do modo como ele enquanto tal pode ser operante" (CRPr, 375). E, assim, nós podemos nos conceber enquanto integrantes de um mundo suprassensível o que significa que somos integrantes de uma "natureza sob a autonomia da razão prática pura" (CRPr, 143).

Assim, defrontamo-nos com dois conceitos de natureza, um que diz respeito às ciências empírico-naturais, na forma como estas tematizam os fenômenos a partir de categorias a priori e, por outro lado, uma natureza suprassensível, que diz respeito a nossa existência prático-ética, ou seja, livre. Como seres humanos, no entanto, pertencemos a esses dois mundos e podemos ser

das as outras coisas, e até de si mesmo, na medida em que ele é afetado por objetos; essa faculdade é a razão (Vernunft). Esta, como pura atividade própria, está acima do entendimento (Verstand) no sentido de que [...] ele não pode contudo tirar da sua atividade outros conceitos senão aqueles que servem apenas para submeter a regras as representações sensíveis e reuni-las por este meio numa consciência [...]. A razão, pelo contrário, mostra, sob o nome das ideias, uma espontaneidade tão pura que por ela ultrapassa de longe tudo o que a sensibilidade pode fornecer ao entendimento, e mostra a sua mais elevada função na distinção que estabelece entre mundo sensível e mundo inteligível, marcando também assim os limites ao próprio entendimento" (FMC, 153).

"O conceito de um mundo inteligível é portanto apenas um ponto de vista que a razão se vê forçada a tomar fora dos fenômenos para se pensar a si mesma como prática, o que não seria possível se as influências da sensibilidade fossem determinantes para o homem, o que porém é necessário na medida em que se lhe não deve negar a consciência de si mesmo como inteligência, por conseguinte como causa racional e atuante pela razão, isto é, livremente eficiente" (FMC, 159). 
considerados a partir desses dois pontos de vista. Por isto Kant afirma que o ser humano é cidadão de dois mundos: "o primeiro, enquanto pertence ao mundo sensível, sob leis naturais (heteronomia); o segundo, como pertencente ao mundo inteligível, sob leis que, independentes da natureza, não são empíricas, mas fundadas somente na razão (FMC, 154). De certa forma, todo o idealismo alemão, tendo suas expressões mais fortes com Fichte, Schelling e Hegel, se defronta e busca superar este dualismo. Fichte e Hegel o fazem ao priorizar a tematização do sujeito e sua constituição, que, por Kant, foi simplesmente pressuposto. Schelling dá uma maior ênfase à unidade originária e comum ao sujeito e sua base material, daí a tematização da natureza assumir uma centralidade em suas teorias. No entanto, no próprio Kant esta preocupação está presente em sua terceira crítica, a Crítica da Faculdade do Juízo, principalmente na segunda parte, onde Kant se detém na tematização da natureza enquanto totalidade orgânica. Busquemos, portanto, evidenciar algumas pistas levantadas pelo próprio Kant.

\section{Natureza enquanto totalidade orgânica}

Se concebermos os dois mundos, inevitavelmente teríamos que nos conceber de forma dualista. Vivemos, no entanto, em apenas um mundo e temos apenas uma razão. Ao mesmo tempo nenhum dos dois mundos nos é suficiente, pois mesmo o mundo fenomênico pressupõe um mundo em si e nossa liberdade só pode se efetivar na medida em que se realiza no mundo fenomênico. Terá, portanto, que ser encontrada uma forma de unificar esse aparente abismo entre natureza suprassensível e a natureza mecânico-causal.

Na Crítica da Faculdade do Juízo (CFJ), Kant enfrenta essa problemática. Na segunda parte desta Crítica, a ideia de organismo adquire uma importância central. Para Kant, todo organismo carrega em si algo que parece ter um fim em si mesmo, no entanto, do ponto de vista da causalidade empíricomatemática, simplesmente não pode ser concebido algo como uma finalidade, uma vez que todas as coisas têm uma causa anteriormente determinada. Por isso, as relações causais não são suficientes para explicar o organismo enquanto uma totalidade em que o todo está para as partes da mesma forma como as partes estão para o todo, e que, enquanto tal, se regenera, se reproduz e transforma. No organismo se vislumbra uma natureza que se determina a partir de si mesma, como se já tivesse previamente um sentido e uma finalidade, como se existisse nela mesma uma razão própria operando. Esse produzir-se a partir de si mesma é, para Kant, muito mais do que um mecanismo, muito mais do que algo pré-programado, é antes "um análogon da vida" (CFJ, 217). Se, por um lado, para todo efeito tem de ter uma causa, o organismo sugere, por outro lado, algo que não se deixa explicar apenas por esta lei.

Para podermos distinguir e compreender algo como orientado por finalidades, ou seja, algo que seja mais do que simples produto de uma cadeia 
causal, Kant sugere o seguinte critério provisório: "uma coisa existe como fim natural quando [...] é causa e efeito de si mesma" (CFJ, 212). E inicia a exposição do tema pelo exemplo de uma árvore. O tema é abordado em três níveis. Primeiro, uma árvore cria uma outra árvore, mas uma árvore cria outra da mesma espécie, ou seja, através dela subsiste a espécie. A árvore parece, pois, ter uma finalidade que é a de preservar a espécie, e isto também pode ser considerado a causa de sua existência. Em segundo lugar, uma árvore se cria a si mesma enquanto indivíduo. Segundo o autor, aquilo que chamamos simplesmente crescimento é muito mais do que simples aumento, é antes a criação (Zeugung) de algo qualitativamente novo. "Esta planta elabora previamente a matéria que ela assimila numa qualidade sua específica, que o mecanismo da natureza que lhe é exterior não pode fornecer, e continua a formar-se através desta substância que na respectiva composição é seu próprio produto" (CFJ, 214). Cria-se, aí, a partir das novas separações e combinações, uma formação original jamais previsível a partir da simples junção dos elementos naturais que a constituem. Há uma forma própria e única de organizar a matéria disponível. Em terceiro lugar, cada parte da árvore, folhas, galhos, raízes etc., se cria a si mesma. Ou seja, cada parte parece ter uma autonomia em relação ao todo, mas, ao mesmo tempo só pode existir por ser parte do todo, sendo que o todo depende destas partes e estas dependem umas das outras, assim como do todo. Além disto, partes podem, devido a alguma dificuldade ou deficiência, se formar de uma forma totalmente nova, trazendo à tona uma criatura totalmente nova.

Segundo Kant, para que algo possa ser compreendido ao mesmo tempo como sendo um produto e ao mesmo tempo causa da natureza, necessitamos da derivação de um conceito apropriado. Até aqui temos as relações causais pensadas pelo entendimento, nas quais cada efeito é causado por algo, sendo que nenhum efeito pode ser causa de si mesmo. Até aqui, tínhamos duas formas de causas: as causa eficiente/atuante (nexus effectivus) e as causas finais (nexus finalis). Uma funcionando como princípio da natureza mecânica e outra da natureza suprassensível, da liberdade humana. O organismo, no entanto, parece não ser explicável por nenhuma destas formas de causalidade, pois as partes só são possíveis na medida em que se relacionam com o todo, o que sugere que o todo carrega consigo um conceito, uma ideia, que determina a própria forma. Esta causa, porém, de forma alguma vem de fora deste organismo. Além disto, as partes são simultaneamente causas e efeitos umas das outras e constituem, assim, a forma do todo. E ao mesmo tempo o todo pode ser simultaneamente determinador de todas as formas e conexões entre as partes. Um organismo, pois, exige um conceito que permita preservá-lo como uma totalidade capaz de se constituir a partir de uma causalidade própria, onde "a conexão das causas eficientes poderia ser ajuizada simultaneamente como efeito mediante causas finais" (CFJ, 216). Cada parte terá que ser pensada como um órgão que gera os outros órgãos e é gerado 
também por estes, "enquanto ser organizado e organizando-se a si mesmo" (CFJ, 216).

Ao comparar mecanismo com organismo, Kant deixa ainda mais clara a especificidade deste último, pois, num mecanismo (num relógio, por exemplo), embora uma peça cause o movimento da outra, uma não é geradora da outra, uma não existe por causa da outra, e o relógio não cria outro relógio. Um organismo contém mais do que apenas força motora, "pelo contrário, possui em si força formadora (bildende) e é uma tal força que ele comunica aos materiais que não a possuem (ela organiza). Trata-se, pois, de uma força formadora que se propaga a si própria, a qual não é explicável só através da faculdade motora (o mecanismo)" (CFJ, 217). Por isto, para Kant, "segundo a constituição do entendimento humano nenhuma outra causa atuante a não ser intencional pode ser aceita para a possibilidade de seres organizados na natureza e o simples mecanismo da natureza não pode de modo nenhum ser suficiente para a explicação destes produtos" (CFJ, 254).

Kant sugere que o conceito (Begriff) necessário para compreender um organismo não é constitutivo do entendimento, como o conhecemos pelas ciências empírico-matemáticas, mas sim "um conceito regulativo para a faculdade do juízo reflexiva" (CFJ, 218) (regulative Begriff für die reflektierende Urteilskraft). Este deveria, antes, ser comparado com as causas finais, existentes em nós enquanto seres livres, do que com o entendimento. É preciso, pois, introduzir um princípio especial, sem o qual não poderíamos compreender nem tematizar os seres organizados de forma apropriada. E este princípio reza: "um produto organizado da natureza é aquele em que tudo é fim e reciprocamente meio. Nele nada é em vão, sem fim ou atribuível a um mecanismo natural cego" (CFJ, 218).

Essa causalidade que modifica, formata, cria, etc., tem, pois, sempre que ser apreciada do ponto de vista teleológico e observada como algo organizado - o que, em último caso, nos obriga a afirmar que "deve o fim da natureza ser estendido a tudo o que se encontra naquilo que é seu produto" (CFJ, 219), o que é o mesmo que dizer que toda a natureza deve ser ajuizada a partir deste princípio ${ }^{6}$, que passa a funcionar como um "fio orientador para a observação desta espécie de coisas da natureza" e vai "para além do mecanismo cego da natureza" (CFJ, 219). Isto, no entanto, significa apenas dizer que as coisas têm uma finalidade enquanto orgânicas, e não que elas existem como se fossem o objetivo e a finalidade da natureza, pois isto exigiria o conhecimento do fim último da natureza, o que, segundo Kant, está muito além de qualquer possibilidade de nosso conhecimento. Não podemos deduzir a necessidade de existência nem de uma folhinha de capim. O que se pode afirmar apenas é que a natureza, enquanto matéria organizada, se determina a partir de si mesma. ${ }^{6}$ "[...]müssen wir sie auch ganz nach diesem Prinzip beurteilen" (KdU A 219). Na tradução de Valério
Rohden e António Marques, aqui utilizada, esta passagem não parece estar clara. 
Como, por nossas categorias do entendimento, não podemos dizer nada em relação aos organismos enquanto organizados por fins, este princípio permanece sempre regulativo, ou seja, serve apenas como um fio condutor de nossa observação, fundamenta uma postura de observadores que permite o acesso aos organismos, ou seja, à natureza enquanto organizada, causada por fins. O que significa apenas "alargar o conhecimento da natureza segundo um outro princípio" (CFJ, 221). Ou, como Kant expressa em outras palavras: "ela acrescenta somente para o uso da razão uma outra espécie de investigação diferente daquela que é feita segundo leis mecânicas, como o objetivo de completar a insuficiência destas últimas, até mesmo em relação à pesquisa empírica de todas as leis particulares da natureza" (CFJ, 225). A física, por exemplo, pode observar o vento, a chuva, etc. e os mecanismos aí inerentes, mas a relação destes fenômenos com fins que também atuam como causas ela não consegue tematizar, simplesmente porque não dispõe de categoria para tal. Aí precisamos do princípio reflexivo, capaz de acrescentar este tipo de natureza a nossa possibilidade de conhecimento (Erkenntnisvermögen). E este conhecimento se funda somente no juízo reflexivo, portanto, tem sua máxima em si mesmo.

A afirmação do princípio segundo o qual os organismos vivos exigem, para poderem ser tamatizados, uma máxima reflexiva, fundada em uma causalidade diferente daquela advinda das categorias do entendimento, leva, inevitavelmente a uma antinomia. Ouando esta antinomia se expressa de forma constitutiva, as duas perspectivas passam a ser excludentes, pois uma reza que "toda a produção de coisas materiais é possível segundo leis simplesmente mecânicas" e a outra, que "algumas dessas mesmas coisas não é possível segundo leis simplesmente mecânicas" (CFJ, 229). E a razão, por si só, não pode optar por uma nem por outra. Esta antinomia, no entanto, quando expressa de forma regulativa, afirma que, por um lado, todas as coisas da natureza devem ser apreciadas, entendidas conforme leis mecânicas e, por outro, que alguns produtos da natureza não podem ser apreciados (beurteilt) por leis mecânicas, pois exigem uma lei de causalidade totalmente outra, a dizer, aquela das causas finais. Dito assim, de forma regulativa, ambas as máximas são possíveis. São apenas princípios diferenciados de investigação da natureza. Por isto a única possibilidade de solução desta antinomia é expressá-la de forma regulativa, pois, assim, as duas máximas não se contradizem, visto que pesquisar até onde for possível, orientado por princípios apenas mecânicos, não impede que, mesmo assim, em alguns casos, sigamos um outro princípio. A única coisa que aí se afirma é que a pesquisa da natureza segundo as categorias do entendimento, ou seja, segundo seus mecanismos, jamais possibilitará a tematização da especificidade de uma finalidade enquanto causa na natureza. E, segundo Kant, nossa razão simplesmente não tem condições de unir estas duas máximas. 
Somente enquanto "fio condutor da reflexão" (CFJ, 230), a máxima do juízo reflexivo é possível. Ela não pode ser averiguada fisicamente, ou seja, determinada pelas categorias de nosso entendimento. A autonomia reflexiva não deveria ser confundida com a heteronomia analítica. Confundir uma com a outra, ou seja, quando com um juízo determinador do entendimento queremos esclarecer algo orientado por fins, ou vice-versa, geramos problemas e antinomias insolúveis. Trata-se apenas de reconhecer a legitimidade de um outro princípio de conhecimento da natureza o qual, "na qualidade de regulativo (não constitutivo), é válido do mesmo modo necessariamente para a nossa faculdade de juízo humana, como se se tratasse de um princípio objetivo" (CFJ, 246).

A possibilidade de um conceito como a finalidade da natureza (Naturzweck) tem de ser encontrado em alguma propriedade da própria razão humana e, assim, ele poderia ser, apesar de subjetivo, universal. Enquanto ideia regulativa, não é de esperar da mesma que se lhe encontre um objeto correspondente na natureza. Segundo Kant, é nisto que a ideia regulativa de um objetivo da natureza se diferencia de outras. E esta diferença consiste no seguinte: "a ideia mencionada não é um princípio da razão para o entendimento, mas sim para a faculdade do juízo, por conseguinte apenas a explicação de um entendimento em geral a possíveis objetos da experiência e na verdade naquela situação em que o juízo não é determinante, mas sim meramente reflexivo" (CFJ, 246). E a possibilidade disto só se torna viável na medida em que nos imaginamos uma outra forma de entendimento. Esta outra forma estaria fundamentada em nossa capacidade de produzir conhecimento também pela contemplação (Anschauung), por onde se produz espontaneamente um conhecimento diferente daquele simplesmente fundamentado em nossos sentidos. Viabiliza-se, assim, a possibilidade de "pensarmos um entendimento intuitivo" (CFJ, 247), que se caracteriza fundamentalmente por ir do "universal sintético (da intuição de um todo como tal) para o particular, isto é, do todo para as partes" (CFJ, 248). É a pressuposição do todo na medida em que este é condição da existência das partes e não simplesmente efeito das forças motoras que interagem nas partes. E é isso que fizemos sempre que nos defrontamos com um ser orgânico. Através desta nossa capacidade a realidade orgânica se tornam tematizável, pois, por mais avanços que façamos em termos de pesquisas baseados na causalidade mecânica, jamais será “dispensável a invocação de um fundamento da geração completamente diferente, nomeadamente a causalidade mediante fins, para a possibilidade de um tal produto. De modo nenhum uma razão humana [...] pode esperar compreender a geração, nem mesmo de uma folhinha de erva a partir de causas simplesmente mecânicas" (CFJ, 251). Ou seja, a diferença entre estas duas formas de conhecimento é uma diferença qualitativa. São conhecimentos resultantes de outros princípios investigativos e levam a concepções qualitativamente diferenciadas de natureza, embora não excludentes. 
Por fim, Kant busca unir estes dois princípios, ou seja, o do mecanismo da matéria e o da teleologia na "técnica da natureza". ${ }^{7}$ Kant não quer, com isto, desconsiderar a natureza como mecanismo, mas também não "passar ao lado do princípio dos fins nos produtos da natureza" (CFJ, 252). Querer reduzir todo o conhecimento da natureza a uma ou outra forma seria, segundo Kant, um fanatismo equivocado. No entanto, quando uma coisa é tomada como sendo um mecanismo, ela não pode mais ser admitida enquanto "produto como fim natural" (CFJ, 353). Ou seja, uma forma de explicação não se coaduna com a outra. É preciso, pois, a fim de encontrar um fundamento comum destes princípios, encontrar algo que esteja fora de ambos, ao qual ambos possam se referir. Kant sugere que este "princípio comum da dedução mecânica, por um lado, e da dedução teleológica, por outro lado, é o supra-sensível que temos que pôr na base da natureza como fenômeno" (CFJ, 254). Deste, contudo, não podemos realizar um conceito positivamente definido, pois tudo o que está a nosso alcance sensível é imediatamente reduzido a uma ou outra forma de conhecimento. Como, em relação ao suprassensível, não são possíveis referências empíricas, conceitos objetivos, "segue-se que a união de ambos os princípios não pode assentar num fundamento da explicação < Explikation> da possibilidade de um produto segundo leis dadas para a faculdade do juízo determinante, mas somente pelo contrário num fundamento do esclarecimento $<$ Eröterung> (Exposition) da mesma para a faculdade do juízo reflexiva" (CFJ, 253). Desta forma, Kant quer, ao menos, assegurar a possibilidade de união destes dois princípios num terceiro, embora não possa demonstrá-lo, "pois concernem a fenômenos que pressupõem um fundamento supra-sensível" (CFJ, 254). Por sermos obrigados a reconhecer esta esfera inacessível a nosso conhecimento, deveríamos, de antemão, assumir uma postura de muita cautela e humildade diante da natureza como um todo, enquanto natureza em si.

Embora o fundamento desta unidade, segundo Kant, esteja no substrato suprassensível da natureza do qual não podermos nada conhecer, podemos conceber esta unidade enquanto conexão das causas finais (Verknüpfung der Endursachen), embora não possamos jamais conhecer como estes dois princípios se unem. Não se trata, portanto, de substituir um princípio pelo outro, mas, com referência ao suprassensível, pelo qual podemos afirmar a natureza como portadora de fins, compreender a relação do organismo com o mecanismo. Ocorre que, "onde são pensados fins como fundamentos da possibilidade de certas coisas, também se têm que aceitar meios cuja lei de ação nada exige por si daquilo que pressupõe um fim, por conseguinte pode ser uma lei mecânica e, todavia, uma causa subordinada a efeitos intencionais" (CFJ, 255). Mesmo nos organismos podemos fazer investigações

Segundo Schmied-Kowarzik (1996, 54 ss.), com o termo técnica Kant quer enfatizar o "trazer para fora de si mesmo", a autoprodução a partir da dinâmica interna, no sentido que a Antiguidade dava a esse termo. 
a partir de leis mecânicas, o que revela uma certa unidade e permite pensarmos ambos os princípios sem precisar abdicar de um ou outro e nem confundi-los.

Embora não possamos dizer até onde podemos avançar com os conhecimentos fundados em princípios mecânicos, o que sabemos é que, por mais que tenhamos este tipo de conhecimento à disposição, não chegaremos jamais aos organismos, enquanto finalidades naturais. O que apenas podemos e deveríamos fazer, segundo Kant, é "subordinar todos aqueles princípios a um princípio teleológico de acordo com a constituição do nosso entendimento" (CFJ, 256). Enfim, por um lado estamos desafiados a conhecer o quanto for possível a natureza do ponto de vista do caráter mecânico, por outro lado, nunca deveríamos perder der vista que todo mecanismo deve ser subordinado à "causalidade segundo fins" (CFJ, 256) ${ }^{8}$. Ou seja, teríamos que partir sempre do pressuposto da natureza enquanto um todo orgânico, que se sobrepõe às leis mecânicas, pois, segundo Kant, há sempre uma organização da natureza que se utiliza do mecanismo, tanto para gerar outras formas organizadas como para manter sua própria ou mesmo para se reestruturar e desenvolver. Existe, portanto, uma primazia da natureza orgânica sobre a mecânica.

Assim nos aproximamos um pouco mais da terceira concepção de natureza de Kant, segundo a qual toda a natureza é um organismo, que, no entanto, faz uso de mecanismos para atingir seus fins. Esta primazia do organismo em relação ao mecanismo poderia fornecer elementos para estabelecermos uma relação diferenciada com a natureza, o que, certamente, continua sendo um grande desafio, inclusive para a filosofia. Seria um exercício muito interessante, por exemplo, agora que chegamos a esta concepção, percorrer o caminho inverso. Ou seja, partindo da natureza como um todo orgânico, chegar aos mecanismos. Certamente isto teria implicações muito diversas para a ciência moderna, assim como para nosso agir éticoprático. Uma vez que tanto nas ciências a natureza é reduzida a fenômenos empírico-causais como em nosso agir ético não levamos em conta a primazia do organismo sobre o mecanismo e raramente buscamos nos compreender enquanto integrados na natureza orgânica, talvez por isto ouçamos tão pouco do Kant da Crítica do Juízo e tanto do Kant da Crítica da Razão Pura. O confronto das três concepções de natureza que, na verdade, são apenas formas de conhecimento da natureza a partir de princípios diferenciados, não só legitima estas variadas formas de conhecimento da natureza, mas também abre perspectivas que ultrapassam a armadilha dualista entre liberdade e necessidade.

A situação de progressiva destruição ambiental na qual nos encontramos atualmente sugere que passemos a atentar mais para o Kant da Crítica do

"[..] doch zuletzt der Kausalität nach Zwecken untergeordnen müssen" (KdU A 360). 
Juízo e das perspectivas e desafio aí apontados. Ou, pelo menos, que ousemos, nas trilhas de Kant, pensar a natureza a partir de outros pontos de vista, que ultrapassem a visão unidimensional baseada em pressupostos exclusivamente empírico-causais. Consequentemente, também teríamos que repensar as própria concepções de sujeito, de sociedade e de natureza, aí pressupostas. Sobre isto, Kant nos deu apenas algumas pistas. As filosofias de Schelling e E. Bloch se aproximaram desta perspectiva, e abrem horizontes, não só para compreendermos a nós enquanto seres orgânicos como parte constitutiva da natureza viva, mas também como seres naturais livres e responsáveis dentro e diante da natureza. Talvez do próprio Kant, enquanto iluminista que foi, ainda possamos afirmar que esteve demasiadamente comprometido com uma postura segundo a qual a única coisa que "queremos aprender da natureza é como empregá-la para dominar completamente a ela e aos homens", como denunciam Adorno e Horkheimer em sua Dialética do Esclarecimento. Ao afirmar e legitimar uma concepção multifacetada de natureza, no entanto, as reflexões de Kant podem contribuir, inclusive, para a superação desta postura.

\section{Bibliografia}

ADORNO, Theodor W.; HORKHEIMER, Max. Dialética do esclarecimento: fragmentos filosóficos. 7. ed. Rio de Janeiro: Jorge Zahar, 1997.

HIRSCHBERGER, Johannes. Geschichte der Philosophie. Altertum und Mittelalter/Neuzeit und Gegenwart. Freiburg im Breisgau: Verlag Herder, s.d.

HÖFFE, Otfried. Immanuel Kant. São Paulo: Matins Fontes, 2005. (Tradução de Chistian Viktor Hamm e Valério Rohden).

HÖSLE, Vitório. Praktische Philosophie in der modernen Welt. Beck: Munique, 1995.

KANT, Immanuel. Crítica da faculdade do juízo (CFJ). Rio de Janeiro: Forense Universitária, 1993. (Tradução de Valério Rohden e António Marques).

KANT, Immanuel. Crítica da da razão prática (CRPr). São Paulo: Martins Fontes, 2003. (Tradução, introdução e notas de Valério Rohden).

KANT, Immanuel. Crítica da razão pura (CRP). Lisboa: Edição da Fundação Calouse Gulbenkian, 2001. (Tradução de Manuela Pinto dos Santos e Alexandre Fradique Morujão).

KANT, Immanuel. Prolegômenos (Prol.). São Paulo: Abril, 1980. Coleção: Os Pensadores. (Tradução de Tania Maria Bernkopf).

KANT, Immanuel. Prolegomena zu einer jeden künftigen Metaphysik, die als Wissenschaft wird auftreten können. In: Werke in sechs Bände: V. 3. Wissenschaftliche Buchgesellschaft: Darmstadt, 1998.

KANT, Immanuel. Kritik der praktischen Vernunft (KdpV). In: Werke in sechs Bände: V. 4. Wissenschaftliche Buchgesellschaft: Darmstadt, 1998.

KANT, Immanuel. Kritik der Urteilskraft (KdU). In: Werke in sechs Bände: V. 5., Wissenschaftliche Buchgesellschaft: Darmstadt, 1998. 
KANT, Immanuel. Kritik der reinen Vernunft (KdrV). In: Werke in sechs Bände: V. II., Wissenschaftliche Buchgesellschaft: Darmstadt, 1998.

SCHELLING, Friedrich. Investigações filosóficas sobre a essência da liberdade humana. Lisboa: Edições 70, 1993

SCHMIED-KOWARZIK, Wolfdietrich. Das dialektische Verhältnis des Menschen zur Natur: Philosophiegeschichtliche Studien zur Naturproblematik bei Karl Marx. Alber: Freiburg 1984.

SCHMIED-KOWARZIK, Wolfdietrich. „Von der wirklichen, von der seyenden Natur": Schellings Ringen um eine Naturphilosophie in Auseinandersetzung mit Kant, Fichte und Hegel. Friedrich Frommann: Stuttgart-Bad Cannstatt, 1996.

SCHÜTZ, Rosalvo. Die abstrahierende Dynamik der modernen Gesellschaft - Konsequenzen für die Beziehung der Menschen untereinander und mit der Natur. Peter Lang: Berna; Berlim; Bruxelas; Frankfurt a. M.; Nova Iorque; Oxford e Viena, 2007. 